\title{
Epidemiology of pain in back and extremities in rural population: A community-based estimation of age- and sex-specific prevalence, distribution, duration and intensity of pain, number of painful sites and seasonality of pain during twelve months in rural Gadchiroli, India
}

\author{
Anand A Bang ${ }^{1}$, \\ Shekhar Y Bhojraj², \\ Mahesh Deshmukh", \\ Vinay R Joshi ${ }^{3}$, \\ Tushar Yermal ${ }^{4}$, \\ Sameer Kalkotwar², \\ Abhay T Bang ${ }^{1}$ \\ ${ }^{1}$ Society for Education, \\ Action and Research \\ in Community Health \\ (SEARCH), Gadchiroli, \\ Maharashtra, India \\ ${ }^{2}$ Spine Foundation, \\ Mumbai, Maharashtra, \\ India \\ ${ }^{3}$ Hinduja Hospital and \\ Research Center, Mumbai, \\ Maharashtra, India \\ ${ }^{4}$ Naraindas Morbai \\ Budhrani Trust, Mumbai, \\ Maharashtra, India
}

\author{
Background Population-based estimates of the burden of pain in back and extremities (PBE) \\ by sex, age, intensity, seasonality and site are lacking from rural India.
}

Methods Two villages were randomly selected from a cluster of 39 villages in Gadchiroli district in India. All residents' $\geq 20$ years of age were surveyed in January 2010 by trained surveyors by making household visits. Information on PBE in the 12 months prior to survey was obtained using a structured, pretested questionnaire.

Results The 12-month period prevalence of PBE was 75\% (95\% confidence interval $\mathrm{CI}=72.54-77.73)$ in men and $91 \%(95 \% \mathrm{CI}=88.66-92.13)$ in women. The prevalence of PBE in the participants $>50$ years was $94 \%$ while that in the age group 20 to 50 years was $79 \%(P<0.05)$. The site with the highest prevalence of pain was low back (women $80 \%$, men $59 \%$ ). The mean number of painful sites per person was 5.42 (95\% $\mathrm{CI}=5.17-5.67)$ in women, 3.68 (95\% CI=3.45-3.90) in men, 3.89 (95\% CI=3.71-4.07) in participants aged 20 to 50 years and $6.48(95 \% \mathrm{CI}=6.11-6.85)$ in those $>50$ years. Among participants across the age and sex groups, the prevalence of mild pain was higher than severe pain at all the anatomical sites. Among various seasons, the highest prevalence of pain was in the rainy season (14\%).

Conclusion The prevalence and the number of painful sites were higher among women and in those $>50$ years of age. The public health interventions for PBE need to focus on these two high risk groups.
Correspondence to:

Dr. Abhay Bang, MD, M.P.H. Director, SEARCH

Shodhgram

PO Gadchiroli

Maharashtra

India 422605

search.gad@gmail.com
Back pain (BP) and musculoskeletal pain (MSP) are the commonest form of chronic pain, causing disability and health care expenditure world over [1-4]. Heavy physical work is a known risk factor for back and musculoskeletal pain [5] and hence agrarian rural communities across the world are at a high risk of BP and MSP [6-8]. Nevertheless, though there was significant data available on the epidemiology of BP and MSP from the developed countries, the data from the developing countries and especially rural and agrarian communities was lacking. To fill this gap, the World Health Organization (WHO) and the International League Against Rheumatism (ILAR) launched a joint initiative called COPCORD (Community Oriented Program for the Control of Rheumatic Diseases). The aim was to conduct population based surveys using uniform methods, focusing on recording symptoms instead of diagnosing diseases. Starting from the Philippines, COPCORD has contributed enormously over the years in providing data from several countries from Asia, South and Central America, and Egypt on the burden and epidemiology of BP and MSP [9].

However, population-based data on the epidemiology of the burden of back and musculoskeletal pain from rural India, focusing on communities which almost exclusively are agrarian and rely on manual labour is lacking, thereby also limiting the possibility of developing appropriate interventions. 
This study, estimating the age and sex specific burden of pain in back and extremities (PBE) in the adult ( $\geq 20$ years) population in rural Gadchiroli in the Maharashtra state in India fills this gap. The burden was measured as, age- and sex-specific a) 12-month period prevalence, b) site specific prevalence, c) number of painful sites per adult, d) duration of pain, e) the intensity of pain and f) seasonality of pain in the rural adult population in Gadchiroli, India, over a period of 12 months.

\section{METHODS}

\section{Study design and sample size}

This study was nested in a population-based, cross-sectional survey of the prevalence of PBE in rural Gadchiroli. The study setting, study design, detail method of sample size calculation, method of village selection including the eligibility criteria are described in detail elsewhere [10].

\section{Questionnaire development, training, quality control and data collection}

A questionnaire in vernacular language (Marathi) was developed to interview the participants and record the following information about: a) episodes of pain in back and extremities at different body sites, b) duration of each pain episode and c) intensity of pain at each site in the 12 months preceding January 2010. The questionnaire was pilot tested in villages that were not part of the study and in the rural clinic of SEARCH. Community health workers (CHWs) were trained in administering the questionnaire and the data were collected from 1 January 2010 to 25 January 2010, details of which are described elsewhere [10].

\section{Statistical methods}

A database was constructed for data entry using FOX PRO Version 2.0 (Microsoft Inc, Redmond, Washington, USA). The data were double entered, validated and checked for inconsistencies. Descriptive statistics included mean, medians and ranges for continuous variables and proportions for categorical variables were calculated. The age and sex specific 12-month period prevalence and the number of painful sites were estimated with their associated 95\% confidence intervals (CI). Student's $t$ test was used for comparison of means. Differences between proportions were assessed using Chi-sqaure test. We followed STROBE guidelines for the reporting of observational studies. Analyses were conducted using Stata 10.0 (Stata Corp, College Station, Texas, USA).

\section{Ethical approval}

The research followed the tenets of the Declaration of Helsinki. Ethical approval for this nested study was granted as part of the main study, by the Institutional Ethical Committee of SEARCH formed according to the guidelines by the Indian Council for Medical Research. Consent was obtained first at the cluster level in the study villages 15 days before starting the survey. The community leaders (Village Council Leaders and members, school-teacher and presidents of microfi-

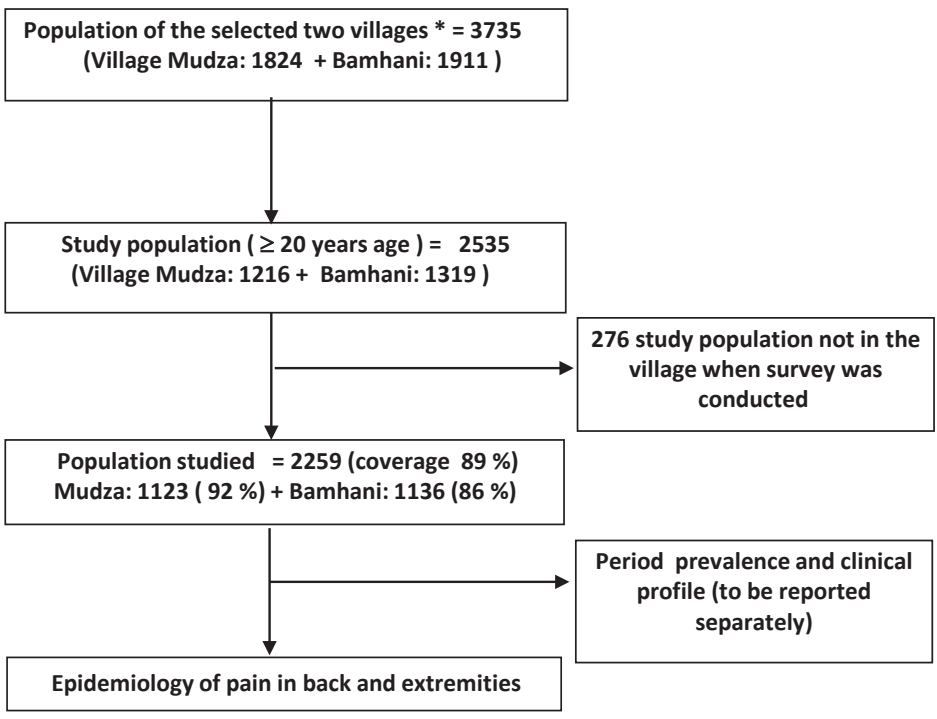

Figure 1. Study design flowchart. *2010 population register. nance self-help groups) were explained the purpose and scope of the study including the benefits to the villagers (availability of referral care in SEARCH clinic and the care through a village clinic). Informed written consent in vernacular language in a standard format was obtained from individual participants after explaining the nature and benefits of the study. The benefits provided during the study included free consultation by spine surgeons and rheumatologists in a clinic conducted in the same village at a later date. For those who needed further evaluation, laboratory investigations, as well as imaging with Magnetic Resonance Imaging (MRI) and x-ray including transport were provided free of cost. For patients needing pharmacotherapy and physiotherapy, these services were provided free of cost and for those needing surgical interventions, such services were provided at significantly subsidized costs. The CHWs discussed these benefits using a printed pamphlet. 
Table 1. Socio-demographic characteristics of the population studied by sex $(n=2259)$

\begin{tabular}{|c|c|c|c|c|c|c|}
\hline \multirow{2}{*}{ CHARACTERISTIC } & \multicolumn{2}{|c|}{$\begin{array}{c}\text { MEN } \\
(\mathrm{N}=1101)^{*}\end{array}$} & \multicolumn{2}{|c|}{$\begin{array}{l}\text { WOMEN } \\
(\mathrm{N}=1158)+\end{array}$} & \multicolumn{2}{|c|}{ TOTAL } \\
\hline & $\mathbf{n}$ & $\%$ & $\mathbf{n}$ & $\%$ & $\mathrm{n}$ & $\%$ \\
\hline Total & 1101 & 49 & 1158 & 51 & 2259 & \\
\hline \multicolumn{7}{|l|}{ Caste: } \\
\hline Schedule castes & 100 & 9.1 & 115 & 9.9 & 215 & 9.5 \\
\hline Schedule tribes & 146 & 13.3 & 172 & 14.9 & 318 & 14.1 \\
\hline Other castes & 855 & 77.7 & 871 & 75.2 & 1726 & 76.4 \\
\hline \multicolumn{7}{|l|}{ Education (years): } \\
\hline Illiterate & 244 & 22.2 & 643 & 55.5 & 887 & 39.3 \\
\hline $1-4$ & 264 & 24.0 & 131 & 11.3 & 395 & 17.5 \\
\hline $5-7$ & 163 & 14.8 & 111 & 9.6 & 274 & 12.1 \\
\hline $8-10$ & 272 & 24.7 & 200 & 17.3 & 472 & 20.9 \\
\hline $11-12$ & 128 & 11.6 & 62 & 5.4 & 190 & 8.4 \\
\hline$>12$ & 30 & 2.7 & 11 & 0.9 & 41 & 1.8 \\
\hline Mean education (standard deviation) & \multicolumn{2}{|c|}{$6(4.3)$} & \multicolumn{2}{|c|}{$4(4.4)$} & \multicolumn{2}{|c|}{$5(4.5)$} \\
\hline \multicolumn{7}{|l|}{ Age (years): } \\
\hline $20-30$ & 353 & 32.1 & 325 & 28.1 & 678 & 30.0 \\
\hline $31-40$ & 229 & 20.8 & 287 & 24.8 & 516 & 22.8 \\
\hline $41-50$ & 222 & 20.2 & 249 & 21.5 & 471 & 20.8 \\
\hline $51-60$ & 146 & 13.3 & 155 & 13.4 & 301 & 13.3 \\
\hline$>60$ & 151 & 13.7 & 142 & 12.3 & 293 & 13.0 \\
\hline Mean age (standard deviation) & \multicolumn{2}{|c|}{$41.6(15.8)$} & \multicolumn{2}{|c|}{$41.8(15.3)$} & \multicolumn{2}{|c|}{$41.7(15.6)$} \\
\hline \multicolumn{7}{|l|}{ Occupation: } \\
\hline Labour & 471 & 42.8 & 528 & 45.6 & 999 & 44.2 \\
\hline Farmer & 375 & 34.1 & 390 & 33.7 & 765 & 33.9 \\
\hline Service & 44 & 4.0 & 25 & 2.2 & 69 & 3.1 \\
\hline Household work & 93 & 8.4 & 100 & 8.6 & 193 & 8.5 \\
\hline Business & 79 & 7.2 & 78 & 6.7 & 157 & 6.9 \\
\hline Other & 39 & 3.5 & 37 & 3.2 & 76 & 3.4 \\
\hline
\end{tabular}

*1108 men out of total 1216 men in village.

$\dagger 1158$ men out of total 1319 men in village.

\section{RESULTS}

The total population of the two villages was 3735 out of which 2535 (67.9\%) were adults $\geq 20$ years of age and were eligible to participate in the study (Figure 1). Of these, 2259 (89\%) were interviewed, 276 (11\%) were either absent from the village (migrated for work) or unable to communicate due to very old age or disability. Total 1101 men (49\%) and 1158 (51\%) women participated in the study. Proportion of illiteracy was higher in women (55\%) participants than men (22.2\%). The demographic characteristics of the participants are described in Table 1.

\section{Prevalence according to sex and age group}

The 12-month period prevalence of back pain was $66 \%(95 \% \mathrm{CI}=63.05-68.73)$ in men and $86 \%$ (95\% CI $=83.42-87.55)$ in women, of pain in the extremities was $63 \%(95 \% \mathrm{CI}=60.19$ $65.98)$ in men and $78 \%$ (95\% CI $=75.83-80.66)$ in women and of back/extremity pain was $75 \%$ (95\% CI $=72.54-77.73)$ in men and 91\% (95\% $\mathrm{CI}=88.66-92.13)$ in women (Table 2). The detailed site-specific prevalence of pain is shown in Table S1 in the Online Supplementary Document. We further classified the participants in five categories of age group (20 to 30, 31 to 40 , 41 to 50,51 to 60 and more than 60 years). Prevalence of PBE increased with increasing age for all the anatomical sites (Table 3, Figure 2, and Table S2 in the Online Supplementary Document).

Table 2. Prevalence of pain at various anatomical sites* by sex (period January 2009 to January 2010, $\mathrm{n}=2259$ )

\begin{tabular}{|c|c|c|c|c|c|c|c|c|}
\hline \multirow{2}{*}{ ANATOMICAL SITE } & \multicolumn{3}{|c|}{ PBE IN MEN (N = 1101) } & \multicolumn{3}{|c|}{ PBE IN WOMEN (N = 1158) } & \multicolumn{2}{|c|}{$\begin{array}{l}\text { DIFFERENCE IN } \\
\text { PREVALENCE }\end{array}$} \\
\hline & n & $\begin{array}{l}\text { \% Prevalence } \\
\text { in male }\end{array}$ & $95 \%$ CI & $\mathbf{n}$ & $\begin{array}{l}\text { \% Prevalence } \\
\text { in female }\end{array}$ & $95 \%$ CI & $\begin{array}{l}\text { Male- } \\
\text { Female }\end{array}$ & $95 \% \mathrm{CI}$ \\
\hline A) Back Pain & 726 & 66 & $(63.68)$ & 991 & 86 & $(83.88)$ & -20 & $(-23,-16)$ \\
\hline Neck & 373 & 34 & $(31.37)$ & 612 & 53 & $(50.56)$ & -19 & $(-23,-15)$ \\
\hline Thoracic & 388 & 35 & $(32.38)$ & 491 & 42 & $40.45)$ & -7 & $(-11,-3)$ \\
\hline Low back & 655 & 59 & $(56.62)$ & 930 & 80 & $(78.83)$ & -21 & $(-25,-17)$ \\
\hline B) Any extremity pain & 695 & 63 & $(60.66)$ & 907 & 78 & $(76.81)$ & -15 & $(-19,-11)$ \\
\hline 1) Superior extremity $\dagger$ & 516 & 47 & $(44.50)$ & 608 & 53 & $(50.55)$ & -6 & $(-10,-2)$ \\
\hline 2) Inferior extremity & 579 & 53 & $(49.55)$ & 838 & 72 & $(67.75)$ & -20 & $(-34,-16)$ \\
\hline C) Any pain (back/extremities) & 828 & 75 & $(72.77)$ & 1048 & 91 & $(89.92)$ & -15 & $(-18,-12)$ \\
\hline
\end{tabular}

PBE - pain in the back and extremities, $\mathrm{CI}$ - confidence interval

*Categories are multiple and overlapping.

$\uparrow$ Any one of the shoulder, arm, elbow, forearm, wrist, hand + fingers, trapezius/scapula.

¥Any one of the hip/buttocks, groin, thigh, knee, leg/calf, ankle, heel, foot + digits.

\section{Number of painful sites}

The mean number of painful sites per woman participant 5.42 (95\% CI=5.17-5.67) was significantly higher than in men 3.68 (95\% CI=3.45-3.90). The mean number of painful sites per participant according to age also significantly increases from $2.81(95 \% \mathrm{CI}=2.58-3.05)$ in the age group 20 to 30 years to $6.62(95 \% \mathrm{CI}=6.10$ 7.14 ) in the age group of $>60$ years (Figure 3, Figure 4, and Tables S3 and S4 in the Online Supplementary 
Table 3. Age group specific prevalence of pain at various anatomical sites* (January 2009 to January 2010)

\begin{tabular}{|c|c|c|c|c|c|c|c|c|c|c|c|c|}
\hline \multirow{2}{*}{ SITE OF PAIN } & \multicolumn{2}{|c|}{$\begin{array}{c}\text { AGE } 20-30 \\
(N=678)\end{array}$} & \multicolumn{2}{|c|}{$\begin{array}{c}\text { AGE } 31-40 \\
(\mathrm{~N}=516)\end{array}$} & \multicolumn{2}{|c|}{$\begin{array}{l}\text { AGE } 41-50 \\
(\mathrm{~N}=471)\end{array}$} & \multicolumn{2}{|c|}{$\begin{array}{l}\text { AGE } 51-60 \\
(\mathrm{~N}=301)\end{array}$} & \multicolumn{2}{|c|}{$\begin{array}{c}\text { AGE }>60 \\
(N=293)\end{array}$} & \multicolumn{2}{|c|}{ TREND VALUE } \\
\hline & $\mathrm{n}$ & $\begin{array}{c}\% \\
\text { prevalence }\end{array}$ & $\mathrm{n}$ & $\begin{array}{c}\% \\
\text { prevalence }\end{array}$ & $\mathrm{n}$ & $\begin{array}{c}\% \\
\text { prevalence }\end{array}$ & $\mathrm{n}$ & $\begin{array}{c}\% \\
\text { prevalence }\end{array}$ & n & $\begin{array}{c}\% \\
\text { prevalence }\end{array}$ & $\begin{array}{c}\mathrm{Z} \\
\text { score }\end{array}$ & $P$-value \\
\hline A) Back pain & 417 & 62 & 398 & 77 & 383 & 81 & 259 & 86 & 260 & 89 & 13.03 & $<0.001$ \\
\hline 1) Neck & 207 & 31 & 229 & 44 & 231 & 49 & 166 & 55 & 152 & 52 & 8.71 & $<0.001$ \\
\hline 2) Thoracic & 200 & 29 & 192 & 37 & 198 & 42 & 134 & 45 & 155 & 53 & 9.29 & $<0.001$ \\
\hline 3) Low back & 367 & 54 & 370 & 72 & 350 & 74 & 252 & 84 & 246 & 84 & 12.72 & $<0.001$ \\
\hline B) Any extremity pain & 368 & 54 & 352 & 68 & 358 & 76 & 261 & 87 & 263 & 90 & 12.95 & $<0.001$ \\
\hline 1) Superior extremity $\dagger$ & 236 & 35 & 243 & 47 & 265 & 56 & 188 & 62 & 192 & 66 & 10.33 & $<0.001$ \\
\hline 2) Inferior extremity & 305 & 45 & 302 & 59 & 318 & 68 & 245 & 81 & 247 & 84 & 12.58 & $<0.001$ \\
\hline C) Any pain (back/extremities) & 471 & 69 & 427 & 83 & 418 & 89 & 280 & 93 & 280 & 96 & 14.14 & $<0.001$ \\
\hline
\end{tabular}

*Categories are multiple and overlapping.

$†$ Any one of shoulder, arm, elbow, forearm, wrist, hand + fingers, trapezius/scapula.

$¥$ Any one of hip/buttocks, groin, thigh, knee, leg/calf, ankle, heel, foot + digits.

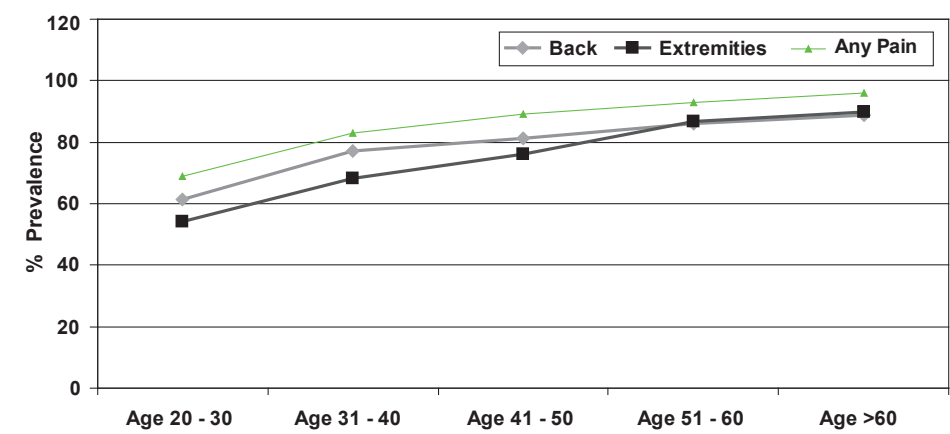

Figure 2. Prevalence of pain in back and extremities by age group (January 2009 to January 2010, $\mathrm{n}=2259$ ). Categories are multiple and overlapping.

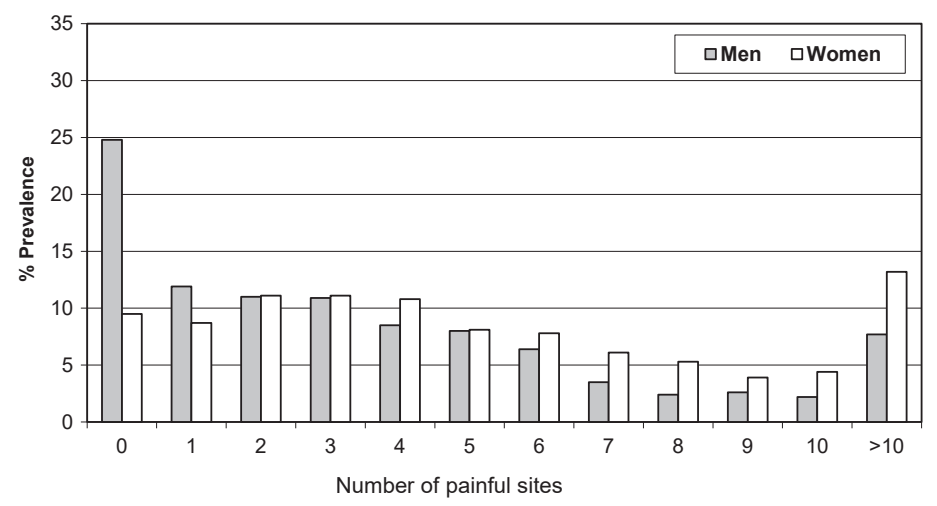

Figure 3. Number of painful sites per participant according to sex (period: 12 months, year 2009-10, $\mathrm{n}=2259$ ).

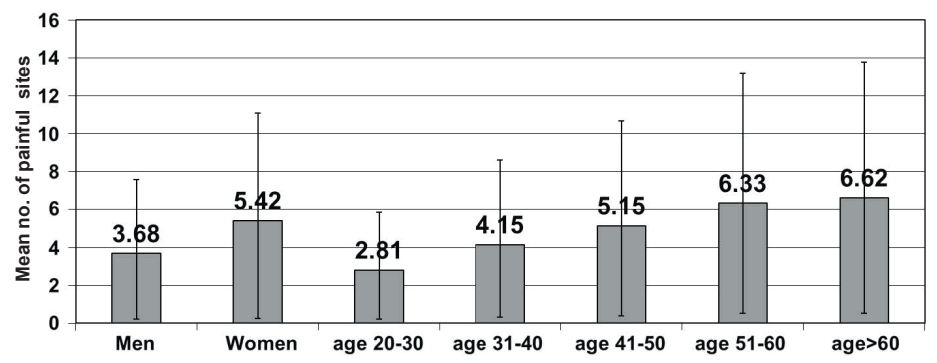

Figure 4. Mean number of painful sites per participant according to age and sex (January 2009 to January 2010, n=2259).
Document). The prevalence of 1 to 5 painful sites was comparable in men and women $(50.3 \%$ and $49.8 \%$ respectively) but the prevalence of 6 to 10 painful sites was significantly higher in women (27.5\%) than men (17.2\%). The prevalence of zero painful sites was more than twice in men (24.8\%) than women (9.5\%), while the prevalence of more than 10 painful sites was almost twice in women (13.2\%) compared to men (7.7\%) (Table S5 in the Online Supplementary Document). Overall, both the prevalence as well as number of painful sites were higher in women and older age group suggestive of a sex and age-related gradient.

\section{Duration of pain}

The mean duration of any pain as well as at the per participants was significantly longer in women (203 days, 95\% $\mathrm{CI}=194.61-212.30)$ than men (127 days, 95\% CI $=118.41-135.91)$ as well as in the participants of $\geq 50$ years ( 232 days, $95 \% \mathrm{CI}=220.04-243.89$ ), compared to the participants in the age group of 20 to 50 years ( 143 days, $95 \% \mathrm{CI}=135.56-150.11$ ). This was consistent across all the main anatomical sites of the neck, thoracic, low back, superior and inferior extremity (Table 4, Figure 5).

Overall, the prevalence of acute (1 to 42 days) and chronic (more than 84 days) pain was significantly higher than the prevalence of sub-acute (43 to 84 days) pain in both men and women at all the anatomical sites. The prevalence of acute pain was higher in men than in women at all the anatomical sites (Table 5). In men, the prevalence of acute pain at neck and superior extremity (23\% and $24 \%$ at respective sites) was higher than that of chronic pain ( $8 \%$ and $18 \%$ at respective sites) while the prevalence of acute $(15 \%)$ and chronic (16\%) thoracic pain was almost equal. In women, the prevalence of chronic pain was higher at all the anatomical sites. In the older participants, the prevalence of chronic pain was higher than acute pain at all the anatomical sites, whereas in the 


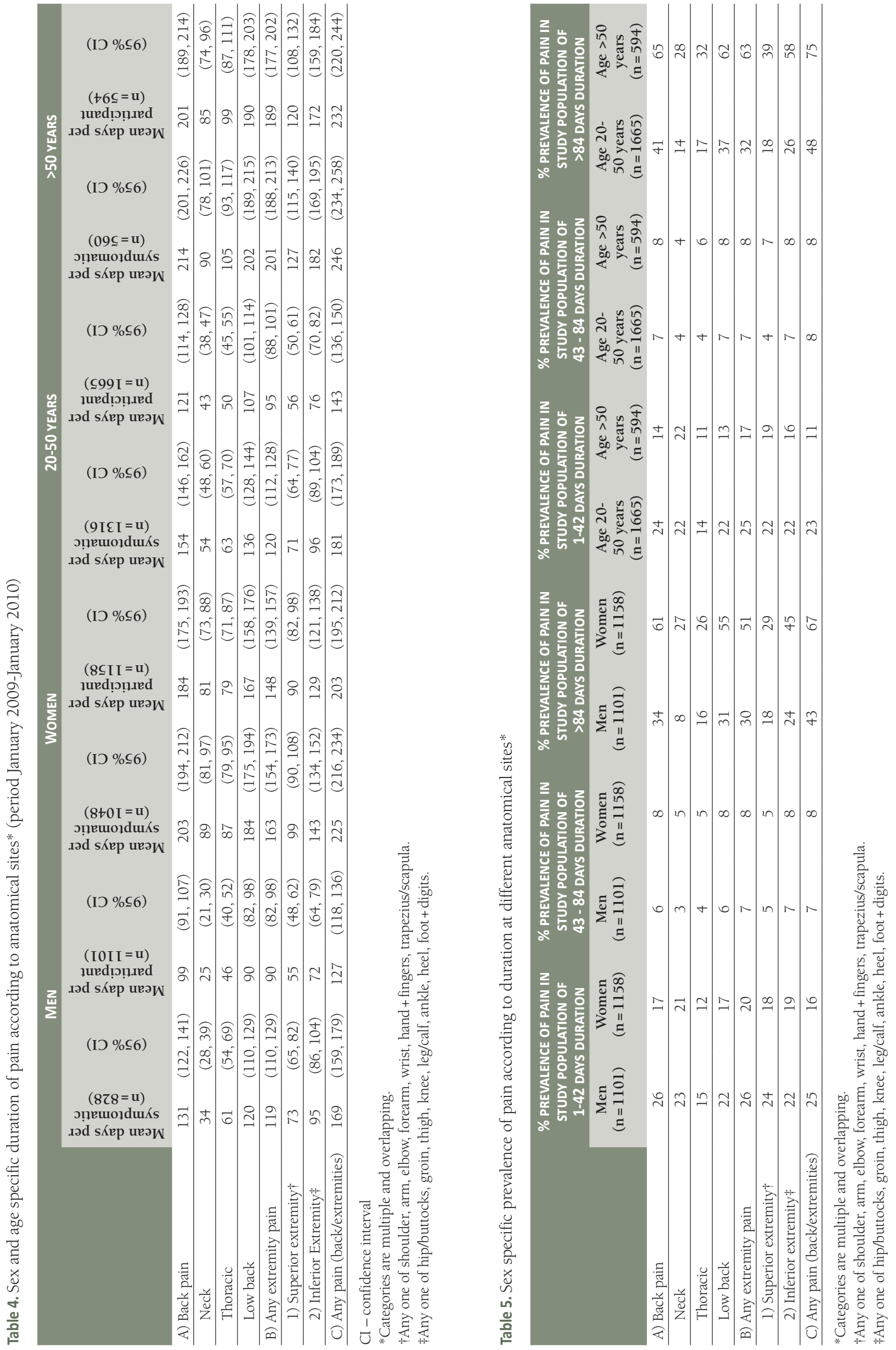




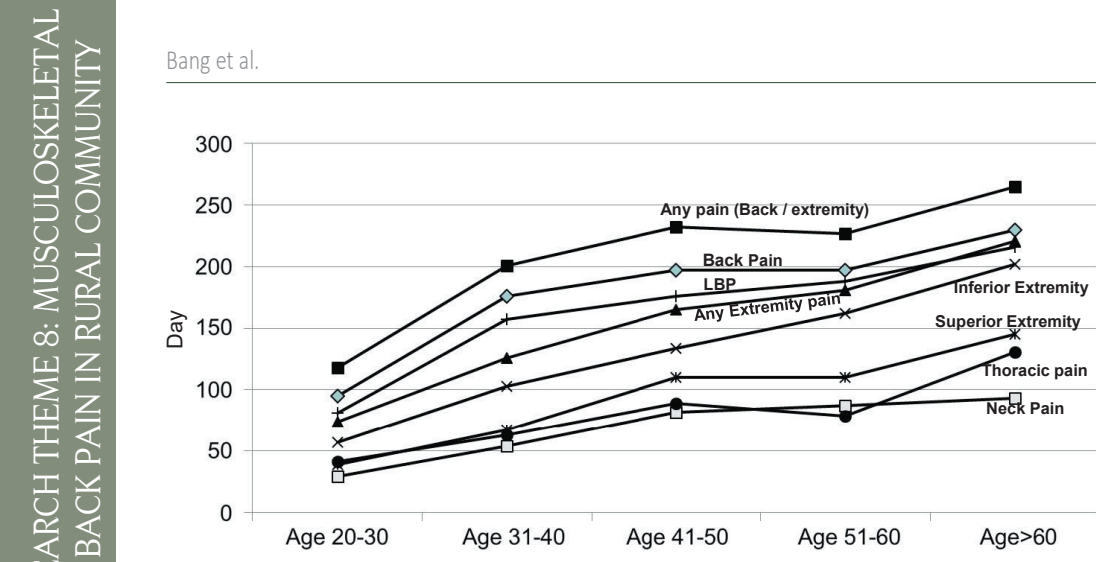

Figure 5. Mean duration of pain in different decades of life in symptomatic cases.

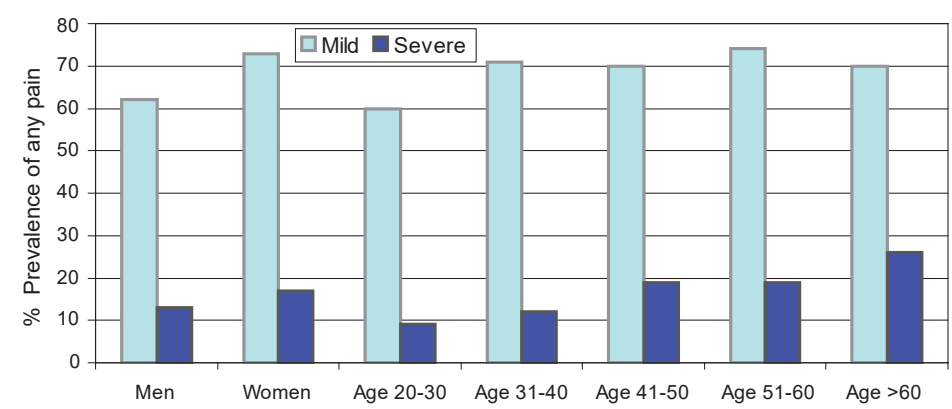

Figure 6. Age and sex specific intensity of any pain (January 2009 to January 2010, $n=2259)$. Categories are multiple and overlapping.

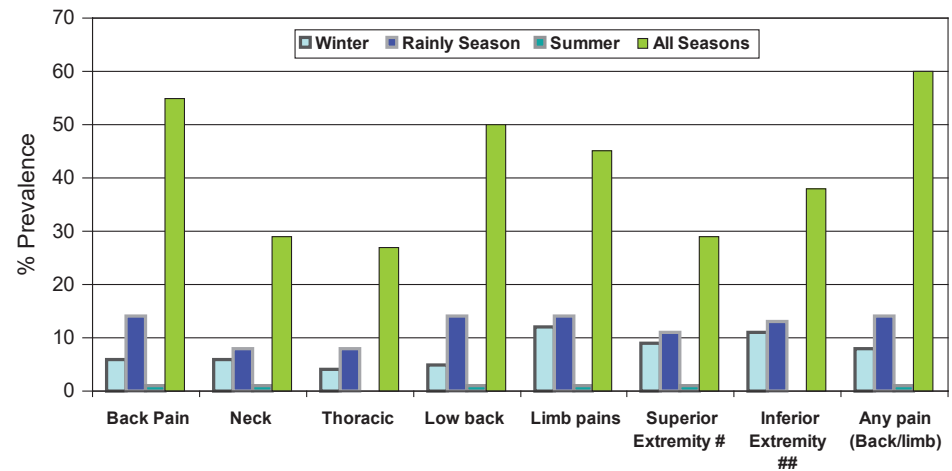

Figure 7. Season specific prevalence of pain at various anatomical sites. Categories are multiple and overlapping. \#Any one of the shoulder, arm, elbow, forearm, wrist, hand + fingers, trapezius/scapula). \#\#Any one of the hip/ buttocks, groin, thigh, knee, leg/calf, ankle, heel, foot + digits). younger participants, specifically at neck (22\%) and the superior extremity (22\%), the prevalence of acute pain was more than chronic pain (14\% and 18\% at respective sites).

\section{Intensity of pain according to sex and age and seasonality of pain}

In both men and women, as well as participants across the age groups, the prevalence of mild pain was higher than severe pain at all the anatomical sites (Figure 6, Table S5 in the Online Supplementary Document). Similarly, for all the anatomical sites, the highest number of participants reported pain in all three seasons. Among those who reported pain during only a specific season, the prevalence of pain was higher in rainy season (Figure 7, Table S6 in the Online Supplementary Document).

\section{DISCUSSION}

The five anatomical sites with the highest prevalence of pain, in both men and women as well as across the age groups were low back, knee, neck, leg and thoracic region. This may be due to higher load bearing activities of rural communities involving these sites. The high prevalence of neck pain can be due to the practice of carrying heavy load (firewood, earth) on head for long distance, especially by women.

The prevalence of acute pain was higher in men and younger participants than women and older for all the anatomical sites. The association between sudden unexpected maximum efforts such as bending, twisting, lifting with low back pain is known [11] and may be contributing to higher prevalence of acute back pain in men who are generally engaged in heavy manual labour. The higher prevalence of acute pain at neck (23\%) and superior extremity (24\%) in men, was probably due to heavy load bearing and digging. Therefore, specific interventions are needed to address the acute pain in this group. Apart from these exceptions, chronicity of pain was the norm corroborating with previously published literature [12]. Constant wear and tear of the bone and muscular frame because of physical hard labour, poor ergonomic postures, and certain nutritional factors may be the possible risk factors, but further studies are needed to identify precise causative pathways.

The prevalence of mild pain was higher than severe pain at all the anatomical sites. This is a hopeful sign, possibly suggestive of good coping mechanisms of the communities. Therefore, simple pain relief measures may yield results in reducing prevalence of PBE. The higher prevalence of low back pain, especially in the rainy season may be due to the bent position women adopt for long hours during planting saplings of paddy and harvesting as well as the heavy load carried by and manual work undertaken by men. Hence ergonomic interventions involving appropriate, low cost technology to reduce the physical burden of paddy cultivation or similar seasonal manual labour specific to the region may be explored as an intervention.

We compared the results from our study with those from other COPCORD studies. The higher prevalence of pain in low back than knee in both the sexes and in different age groups was similar to results of COPCORD studies from China [13], Indonesia [14], aborigines in Australia [15] and Bangladesh (8), but different from 
the findings of the Indian COPCORD series in which the prevalence of knee pain was higher than low back $[7,9]$. In general, women have a higher burden of acute and nonfatal chronic morbidities [16], especially temporary and persistent pain [17]. Our study also reported higher prevalence of pain in women at all the anatomical sites. This corroborated with other COPCORD studies [18-21], even though it differed from smaller set of studies reporting higher prevalence of back pain in men [22-24] or equal between sexes [25]. The highest prevalence of pain during the rainy season in our study differs from the Indian COPCORD study [19] in which the highest prevalence was in winter. This could be due to higher proportion of agrarian population in our study which is engaged in manual agricultural work the most during monsoon.

The factors affecting higher prevalence of PBE in our population would include higher prevalence of osteoporosis in women with increasing age compared to men [1]. This may have may have contributed to the higher prevalence of musculoskeletal pains in the women, especially in the older age group. Prevalence of pain at particular sites, especially at knee may be higher in women due to higher proportion of osteoarthritis, for which female sex, low body weight and lifting are known risk factors [26]. Nevertheless, this does not fully explain the difference in prevalence of knee pain between women and men, as the other risk factors such as heavy lifting and alcohol abuse [26] are also common in men. It has been reported that the causative factors of low back pain in African population differed from those in the Western population [27]. Similarly, therefore, the Indian population may have certain specific risk factors especially considering the less muscle mass and height as well as role of genetic factors [27].

To the best of our knowledge, this is the first study from rural India reporting in detail the population-based epidemiology of PBE including prevalence according to age and sex, the number of painful sites, duration, intensity as well as the seasonality of pain. The previous studies on epidemiology of PBE were primarily from peri-urban and relatively affluent rural areas [28], restricted to a certain type of labour population only, such as drill worker, cashew worker or jute worker [29-31], or were not population based [32]. However, it is possible that the epidemiology of PBE would vary according to different rural parts of India due to regional differences, the nature of occupational work communities are engaged in, socioeconomic status and access to care. In this aspect, the participants in this study can be considered more representative of the larger agrarian Indian communities with its significant dependence on manual labour.

This study, nested in the larger study to identify the overall 12 months period prevalence had several strengths which included random selection of the two study villages, high participation rate of the participants (89\%) and data collection by CHWs with more than 15 years of experience using a well-tested, structured and robust questionnaire with rigorous quality control. These lend confidence to the estimates obtained. The key limitations of our study are the possibility of recall loss in reporting of pains from preceding 12 months and routine treatment of pains using aspirin by CHWs in these villages. Nevertheless, both these limitations would have resulted in underestimation and not overestimation of the burden of the problem.

\section{CONCLUSION}

This population-based study from rural Gadchiroli describes the epidemiology of pain in back and extremities, identifies a significant gender and age related burden and underlines the chronic nature of the problem. It also provides clues to the different target populations (younger vs older and men vs women) for public health intervention. Further larger population based studies from different parts of rural India are needed to identify the regional estimates of the epidemiological variation in the profile of PBE as well as risk factors to understand the causation and explore intervention for PBE in rural Indian communities.

Acknowledgements: We thank the people, community health workers, volunteers and leaders of the village Mudza and Bamhani who participated in the study and made all the arrangements. We thank Dr Rani Bang, SEARCH, Gadchiroli for her support in conceiving and conducting the study. We thank Dr Yogesh Kalkonde for reviewing the manuscript.

Funding: The study was funded by Sir Dorabji Tata Trust, the Spine Foundation, Mumbai, and SEARCH, Gadchiroli, India.

Author Contributions: Conceived and designed the study: AAB, ATB, SYB, VRJ, MD, SK. Conducted the study: AAB, MD, TY, ATB. Analyzed the data: MD, AAB, ATB. Contributed materials / analysis tools: ATB, SYB, SK, VRJ. Wrote the draft manuscript: AAB. Reviewed the manuscript: ATB.

Competing interests: The authors have completed the ICMJE Disclosure of Interest form (available upon request from the corresponding author), and declare no conflicts of interest.

\section{Additional material}

Online Supplementary Document 
1 Woolf AD. The Bone and Joint Decade 2000-2010. Ann Rheum Dis. 2000;59:81-2. Medline:10666159 doi:10.1136/ard.59.2.81

2 Ehrlich GE. Low back pain. Bull World Health Organ. 2003;81:671-6. Medline:14710509

3 Murray CJL, Vos T, Lozano R, Naghavi M, Flaxman AD, Michaud C, et al. Disability-adjusted life years (DALYs) for 291 diseases and injuries in 21 regions, 1990-2010: a systematic analysis for the Global Burden of Disease Study 2010. Lancet. 2012;380:2197-223. Medline:23245608 doi:10.1016/S0140-6736(12)61689-4

4 Campbell C, Muncer SJ. The causes of low back pain: a network analysis. Soc Sci Med. 2005;60:409-19. Medline:15522495 doi:10.1016/j.socscimed.2004.05.013

5 Barrero LH, Hsu Y-H, Terwedow H, Perry MJ, Dennerlein JT, Brain JD, et al. Prevalence and Physical Determinants of Low Back Pain in a Rural Chinese Population. Spine. 2006;31:2728-34. Medline:17077743 doi:10.1097/01.brs.0000244583.35982.ea

6 Louw QA, Morris LD, Grimmer-Somers K. The prevalence of low back pain in Africa: a systematic review. BMC Musculoskelet Disord. 2007;8:105. Medline:17976240 doi:10.1186/1471-2474-8-105

7 Chopra A, Abdel-Nasser A. Epidemiology of rheumatic musculoskeletal disorders in the developing world. Best Pract Res Clin Rheumatol. 2008;22:583-604. Medline:18783739 doi:10.1016/j.berh.2008.07.001

8 Haq SA, Darmawan J, Islam MN, Uddin MZ, Das BB, Rahman F, et al. Prevalence of rheumatic diseases and associated outcomes in rural and urban communities in Bangladesh: a COPCORD study. J Rheumatol. 2005;32:348-53. Medline:15693098

9 Chopra A. Community rheumatology in India: a COPCORD driven perspective. Indian J Rheumatol. 2009;4:119-26. doi:10.1016/S0973-3698(10)60192-6

10 Bang AA, Bhojraj SY, Deshmukh M, Joshi VR, Yarmal T, Kalkotwar S, et al. Burden of pain in back and extremities in rural population: A community-based estimation of 12 - month period prevalence, distribution and duration of pain in rural Gadchiroli, India. J Glob Health. 2021;11:12002. doi:10.7189/jogh.11.12002

11 Manchikanti L. Epidemiology of low back pain. Pain Physician. 2000;3:167-92. Medline:16906196 doi:10.36076/ ppj.2000/3/167

12 Fillingim RB, King CD, Ribeiro-Dasilva MC, Rahim-Williams B, Riley JL. Sex, Gender, and Pain: A Review of Recent Clinical and Experimental Findings. J Pain. 2009;10:447-85. Medline:19411059 doi:10.1016/j.jpain.2008.12.001

13 Zeng QY, Chen R, Xiao ZY, Huang SB, Liu Y, Xu J, et al. Low prevalence of knee and back pain in southeast China; the Shantou COPCORD study. J Rheumatol. 2004;31:2439-43. Medline:15570648

14 Darmawan J, Valkenburg HA, Muirden KD, Wigley RD. Epidemiology of rheumatic diseases in rural and urban populations in Indonesia: a World Health Organisation International League Against Rheumatism COPCORD study, stage I, phase 2. Ann Rheum Dis. 1992;51:525-8. Medline:1586254 doi:10.1136/ard.51.4.525

15 Minaur N, Sawyers S, Parker J, Darmawan J. Rheumatic disease in an Australian Aboriginal community in North Queensland, Australia. A WHO-ILAR COPCORD survey. J Rheumatol. 2004;31:965-72. Medline:15124258

16 Svensson HO, Andersson GB. Low back pain in forty to forty-seven year old men. I. Frequency of occurrence and impact on medical services. Scand J Rehabil Med. 1982;14:47-53. Medline:6213033

17 Unruh AM. Gender variations in clinical pain experience. Pain. 1996;65:123-67. Medline:8826503 doi:10.1016/03043959(95)00214-6

18 Das SK, Srivastava R, Kumar P, Srivastava S, Alok R, Bhattacharya D, et al. P56 The incidence of self reported musculoskeletal problems in rural and urban population of Lucknow (North India). Indian J Rheumatol. 2006;1:165-6. doi:10.1016/S09733698(10)60285-3

19 Chopra A, Saluja M, Patil J, Tandale HS. Pain and disability, perceptions and beliefs of a rural Indian population: A WHO-ILAR COPCORD study. WHO-International League of Associations for Rheumatology. Community Oriented Program for Control of Rheumatic Diseases. J Rheumatol. 2002;29:614-21. Medline:11908580

20 Davatchi F, Tehrani Banihashemi A, Gholami J, Faezi ST, Forouzanfar MH, Salesi M, et al. The prevalence of musculoskeletal complaints in a rural area in Iran: a WHO-ILAR COPCORD study (stage 1, rural study) in Iran. Clin Rheumatol. 2009;28:126774. Medline:19629618 doi:10.1007/s10067-009-1234-8

21 Zeng QY, Chen R, Darmawan J, Xiao ZY, Chen SB, Wigley R, et al. Rheumatic diseases in China. Arthritis Res Ther. 2008;10:R17. Medline:18237382 doi:10.1186/ar2368

22 Fabunmi AA, Aba SO, Odunaiya NA. Prevalence of low back pain among peasant farmers in a rural community in South West Nigeria. Afr J Med Med Sci. 2005;34:259-62. Medline:16749358

23 Lavsky-Shulan M, Wallace RB, Kohout FJ, Lemke JH, Morris MC, Smith IM. Prevalence and functional correlates of low back pain in the elderly: the Iowa 65+ Rural Health Study. J Am Geriatr Soc. 1985;33:23-8. Medline:3155530 doi:10.1111/j.1532-5415.1985.tb02855.x

24 Laslett M, Crothers C, Beattie P, Cregten L, Moses A. The frequency and incidence of low back pain/sciatica in an urban population. N Z Med J. 1991;104:424-6. Medline:1833679

25 Burton AK, Balagué F, Cardon G, Eriksen HR, Henrotin Y, Lahad A, et al. Chapter 2. European guidelines for prevention in low back pain: November 2004. Eur Spine J Off Publ Eur Spine Soc Eur Spinal Deform Soc Eur Sect Cerv Spine Res Soc. 2006; 15 Suppl 2:S136-168.

26 WHO Scientific Group on the Burden of Musculoskeletal Conditions at the Start of the New Millennium. Geneva: WHO; 2003.

27 Stelzhammer B. Community-based prevalences of headache and backache in a rural Tanzanian community - epidemiology and characteristics. Thesis Dr Med universae. Med Univ Innsbruck. 2005.

28 Chopra A, Patil J, Billempelly V, Relwani J, Tandle HS. Prevalence of rheumatic diseases in a rural population in western India: a WHO-ILAR COPCORD Study. J Assoc Physicians India. 2001;49:240-6. Medline:11225138

29 Tiwari RR, Saha A. An epidemiological study of low back pain among oil drilling workers in India. Toxicol Ind Health. 2014;30:60-3. Medline:22740620 doi:10.1177/0748233712451771 
30 Girish N, Ramachandra K, Arun GM, Asha K. Prevalence of musculoskeletal disorders among cashew factory workers. Arch Environ Occup Health. 2012;67:37-42. Medline:22315934 doi:10.1080/19338244.2011.573020

31 Sett M, Sahu S. Study on work load and work-related musculoskeletal disorders amongst male jute mill workers of West Bengal, India. Work. 2012;42:289-97. Medline:22699196 doi:10.3233/WOR-2012-1352

32 Sharma SC, Singh R, Sharma AK, Mittal R. Incidence of low back pain in workage adults in rural North India. Indian J Med Sci. 2003;57:145-7. Medline:14510345 